\title{
Responses of SOM decomposition to changing temperature in Zoige alpine wetland, China
}

\author{
Jingyue Xue $\cdot$ Hongxuan Zhang $\cdot$ \\ Nianpeng He $\cdot$ Youmin Gan $\cdot$ Xuefa Wen $\cdot$ Jie Li $\cdot$ \\ Xuelian Zhang $\cdot$ Peibin Fu
}

Received: 29 August 2014/ Accepted: 4 June 2015/Published online: 23 August 2015

(C) Springer Science+Business Media Dordrecht 2015

\begin{abstract}
Alpine wetlands are considered to be very sensitive to future climate warming. Understanding changes in decomposition rates $(R s)$ of soil organic matter $(\mathrm{SOM})$ and temperature sensitivity $\left(Q_{10}\right)$ in alpine wetlands, under the scenarios of a warming climate and decreasing soil moisture, is important for predicting their carbon (C) budget. Here, we established three sampling transects from wetland edge to meadow in the Zoige alpine wetlands in China, which represented the gradients of decreasing soil moisture. We conducted an incubation experiment $\left(5-25{ }^{\circ} \mathrm{C}\right)$ to explore changes in $Q_{10}$ with the degradation process from alpine wetland to alpine meadow. The results showed that temperature significantly influenced $R s$ in all locations. $R s$ first increased from site I to site IV and then decreased from site IV to site V. However, $Q_{10}$ and activation energy $\left(E_{a}\right)$ showed no apparent trends
\end{abstract}

J. Xue $\cdot$ H. Zhang $(\bowtie)$

Sichuan Academy of Grassland Science,

Chengdu 611731, China

e-mail: zhanghx@189.cn

J. Xue · Y. Gan $(\varangle) \cdot$ X. Zhang · P. Fu

College of Animal Science and Technology, Sichuan

Agricultural University, Yaan 625014, China

e-mail: ganyoumin1954@163.com

N. He $(\bowtie) \cdot$ X. Wen $\cdot$ J. Li

Key Laboratory of Ecosystem Network Observation and Modeling, Institute of Geographic Sciences and Natural Resources Research, CAS, Beijing 100101, China

e-mail: henp@igsnrr.ac.cn with soil coming from sites along a moisture gradient. Overall, the $Q_{10}$ values in the wetland (sites 1.50) were significantly lower than that of the meadow (1.83); similar trends were observed for $E_{a}$. In addition, $E_{a}$ exhibited a negative logarithmic relationship with $\mathrm{C}$ quality indices in all locations, which suggested that the $\mathrm{C}$ quality-temperature hypothesis is applicable to both alpine wetlands and meadows. These findings provide a theoretical foundation for predicting the potential influences of warming climate on soil $\mathrm{C}$ turnover and storage in alpine wetlands.

Keywords Activation energy - Alpine wetland . Carbon quality-temperature hypothesis - Soil organic carbon $\cdot$ Temperature sensitivity $\cdot$ Soil moisture

\section{Introduction}

It is estimated that wetlands store approximately 20-30\% of terrestrial soil organic carbon (SOC), although they occupy only $5-8 \%$ of the land surface (Mitsch and Gosselink 2007). Wetland degradation, especially decreasing area and soil water content, has been widely observed in association with warming climate (Froend 1999; Jin et al. 2007), which is accompanied by the reduction of productivity, biodiversity (Hart and Lovvorn 2000), and soil nutrients (Gilbert et al. 2004). Gillespie et al. (2014) pointed out that under warming climate, higher decomposition of soil organic matter (SOM) and a lower water table 
would occur in subarctic wetlands and result in increased $\mathrm{CO}_{2}$ release in this region. Therefore, the degradation of wetlands has an immediate impact on their $\mathrm{C}$ budget, and it is necessary to take effective measures to restore them (Limpens et al. 2008).

Few studies have investigated the effect of and lowered water table on SOM decomposition in alpine wetlands. Theoretically, changes in soil moisture play important roles in regulating SOM decomposition. Soil water films may promote diffusion of extracellular enzymes and soluble organic carbon (C) substrates and may increase substrate availability in micro-sites when water content is moderate (Davidson and Janssens 2006; Toberman et al. 2008). Gao et al. (2008) demonstrated that soil moisture strongly influences microbial activity and SOM decomposition in wetlands. Numerous researchers have found that the content and quality of SOM may influence SOM decomposition to large extent in alpine wetlands where temperature and moisture are not limiting (de Bruijn and Butterbach-Bahl 2010; Huo et al. 2013; Kirschbaum 2006).

Temperature is a key factor influencing the decomposition rates $(R s)$ of SOM decomposition (Jones et al. 2003; Lenton and Huntingford 2003). The temperature sensitivity $\left(Q_{10}\right)$ has been widely used to depict the response of SOM decomposition to changing temperature (Bauer et al. 2008; He et al. 2013; Kirschbaum 2000). Some studies have demonstrated that $Q_{10}$ is important for predicting the $\mathrm{C}$ budget in terrestrial ecosystems under warming scenarios, and some experimental studies have explored the spatiotemporal patterns of the $Q_{10}$ values in terrestrial ecosystems (Davidson and Janssens 2006; Fang et al. 2005; Fierer et al. 2006; Gillabel et al. 2010). However, the response of $Q_{10}$ values to the degradation in alpine wetlands have not been investigated to date. Furthermore, on basis of the principles of thermodynamics and enzyme kinetics, the $\mathrm{C}$ quality-temperature hypothesis (CQT) has been proposed to explain the mechanisms of SOM decomposition and substrate quality (Conant et al. 2008; Davidson and Janssens 2006; Xiang and Freeman 2009). This hypothesis assumes that molecular complexity of the substrate is associated with the quality of organic matter, and lower-quality substrates have recalcitrant molecular structure and higher activation energy $\left(E_{a}\right)$ and thus a greater $Q_{10}$ value. As the temperature increases, more molecules reach or exceed their $E_{a}$; however, there is a decline in the relative increase in the fraction of molecules with sufficient energy to react, indicating that $Q_{10}$ decreases with increasing temperature (Davidson and Janssens 2006). The CQT hypothesis has been validated by some studies using different approaches (Bosatta and Agren 1999; Craine et al. 2010a, b; Mikan et al. 2002; Xu et al. 2012). However, whether or not the CQT hypothesis could be applicable to alpine wetlands has not been verified.

The Zoige alpine wetland is located at the eastern edge of the Qinghai-Tibet Plateau and is the largest alpine wetland in China (Fei et al. 2006). SOM decomposition in alpine wetlands is expected to increase to some extent under climatic warming scenarios accompanied by decreasing wetland area and water table. In this study, we established three transects from wetland edge to meadow along the gradients of decreasing soil moisture, and conducted an incubation experiment to explore the changes in $R s$ and $Q_{10}$. Our main objectives were to (1) investigate the changing trends of $R s$ with the degradation of the alpine wetland, (2) explore the changes in $Q_{10}$ and $E_{a}$ with the alpine wetland degradation, and (3) verify the applicability of the CQT hypothesis in the alpine wetland and meadow.

\section{Materials and methods}

Study area

The Zoige Wetlands $\left(32^{\circ} 56^{\prime}-34^{\circ} 19^{\prime} \mathrm{N}, 102^{\circ} 08^{\prime}-\right.$ $\left.103^{\circ} 39^{\prime} \mathrm{E}\right)$ is located at the eastern edge of the Qinghai-Tibet Plateau in China and is the largest alpine wetland in China. The altitude of the study area is approximately $3,400-3,800 \mathrm{~m}$ a.s.1. This region has a typical humid and semi-humid continental monsoon climate of plateau cold temperate zone. The mean annual temperature is approximately $0.7{ }^{\circ} \mathrm{C}$, and the mean annual precipitation is $600-800 \mathrm{~mm}$ (Bai et al. 2013). The coldest month is January $\left(-10.6^{\circ} \mathrm{C}\right)$ and the warmest month is July $\left(10.8^{\circ} \mathrm{C}\right)$. The major vegetation types are marsh-meadow and meadow. The marsh-meadow is dominated by Carex muliensis, $C$. lasiocarpa, and C. meyeriana, whereas the meadow is dominated by Poaceae grasses such as Elymus dahuricus, and Poa pratensis (Huo et al. 2013).

Soil samples were collected in July 2013 in Huahu Lake, Zoige, Sichuan Province. Huahu Lake is the 
highest alpine lake in Zoige and has typical watertable gradients from alpine wetland to alpine meadow (Chen et al. 2011). A decline in wetland area and water table has been observed in past decades in this region (Tan et al. 2012; Tang et al. 2012; Zhang et al. 2011).

Sampling and pretreatment

We first established three transects from the edge of Huahu Lake to the alpine meadow, with five sampling locations (I, II, III, IV, and V) in each transect to represent the gradients of decreasing soil moisture. Sampling sites I-IV were in the alpine wetland region, and site $\mathrm{V}$ was in the alpine meadow region (Fig. 1). All sampling sites had been subjected to long-term free grazing by yak, according to local grazing tradition. Plant community composition and aboveground productivity, and coverage showed that vegetation was in good condition in locations I-IV, whereas $\mathrm{V}$ was slightly degraded as a result of higher grazing intensity (Table 1 ).

We measured soil water content, plant species composition, and aboveground biomass in six quadrats $(50 \times 50 \mathrm{~cm})$ at random locations in each sampling site. We recorded plant coverage, density, height, and frequency in three quadrats per sampling location; aboveground biomass was clipped at ground level in all quadrats. Three soil samples were taken at each sampling location in the $0-10$ and $10-30 \mathrm{~cm}$ soil layers using an auger ( $7 \mathrm{~cm}$ diameter). Soil samples were sieved $(<2 \mathrm{~mm})$, and visible roots and organic debris were removed by hand. Approximately $100 \mathrm{~g}$ of soil for each sample was air-dried for analysis of soil properties $(\mathrm{C}$, nitrogen $(\mathrm{N})$, and $\mathrm{pH})$. The remaining soil samples were stored at $4{ }^{\circ} \mathrm{C}$.

Chemical analysis and incubation experiment

Soil water holding capacity (WHC, \%) and gravimetric water content $(\%)$ were measured in the laboratory. The concentrations of soil total $\mathrm{C}$ and total $\mathrm{N}$ were measured using a Vario Max $\mathrm{CN}$ elemental analyzer (Vario Max CN, Elementar Company, Germany). Soil pH was measured in a soilwater slurry $(1: 2.5, \mathrm{w} / \mathrm{w})$ with an Ultrameter-2 $\mathrm{pH}$ meter (Myron L. Company, California, USA).

To prevent the thermal adaptation of soil microorganisms (Sierra et al. 2010), the 56-d laboratory incubation was conducted at five temperatures $(8,13$, 18,23 , and $28{ }^{\circ} \mathrm{C}$ in the daytime; $5,10,15,20$, and $25^{\circ} \mathrm{C}$ at night). A total of 225 soil samples (3 transects $\times 5$ sampling sites $\times 3$ temperatures $\times 3$

Fig. 1 Sampling locations in the Zoige wetland, China

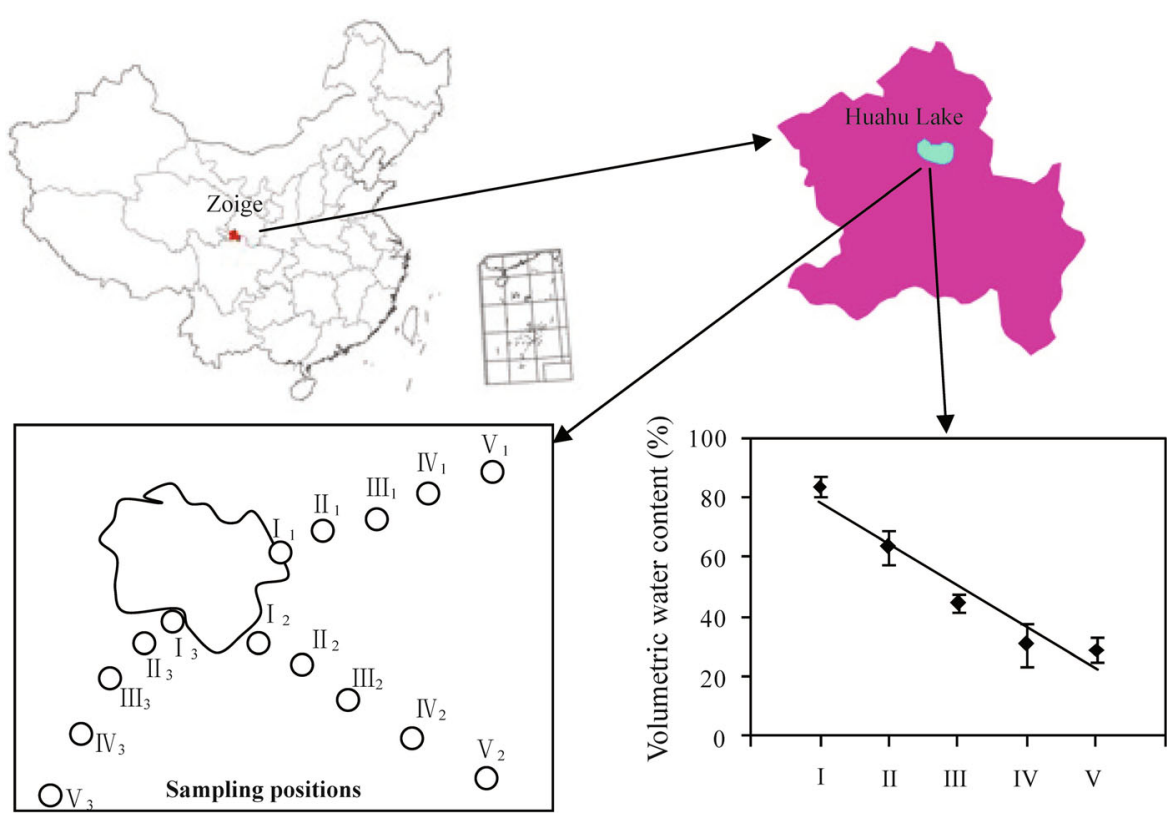




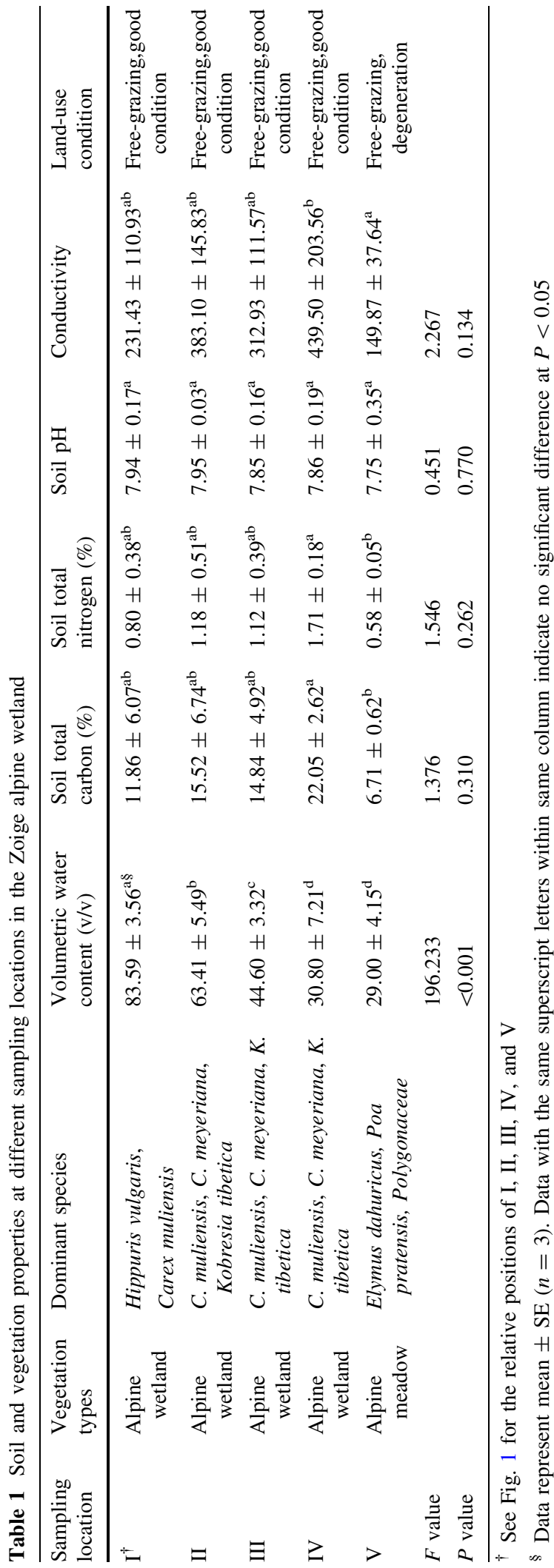

replicates) were used in the incubation experiment. In brief, $40 \mathrm{~g}$ of fresh soil, adjusted to $55 \% \mathrm{WHC}$, was placed into incubation bottles $(5 \mathrm{~cm}$ diameter, $10 \mathrm{~cm}$ tall) and mixed with $10 \mathrm{~g}$ quartz sand. The samples were pre-incubated at $20{ }^{\circ} \mathrm{C}$ and constant humidity ( $80 \%$ ) for 1 week followed by the incubation temperature for 8 weeks to measure Rs. During the 56-d experiment, $R s$ were measured 10 times, on days 0,1 , $3,5,7,14,21,28,42$, and 56. Soil moisture was adjusted at 3-4 day intervals on a weight basis.

An automatic system has been developed to measure $R s$ (He et al. 2013). In practice, $R s$ ( $\mu \mathrm{g} \mathrm{C}$ $\mathrm{g}^{-1} \mathrm{~h}^{-1}$ ) was calculated from the slope of $\mathrm{CO}_{2}$ concentration and conversion factors as follows:

$R s=\frac{C \times V \times \alpha \times \beta}{m}$

where $C$ is the slope of the change in $\mathrm{CO}_{2}$ concentration, $V$ is the volume of the incubation bottle and gas tube, $m$ is the soil weight $(\mathrm{g}), \alpha$ is the conversion coefficient for $\mathrm{CO}_{2}$ mass, and $\beta$ is a conversion coefficient of time.

Calculation of $E_{a}$ and $Q_{10}$

The $Q_{10}$ values were calculated using the following exponential equations (Fierer et al. 2003):

$R s=Q \times e^{b T}$

$Q_{10}=e^{10 b}$

where $T$ is temperature $\left({ }^{\circ} \mathrm{C}\right) ; Q$ is $\mathrm{C}$ quality index of $\mathrm{SOM}$ (the exponential constant or activity at $0{ }^{\circ} \mathrm{C}$ ); and $b$ is the exponential fit parameter for the slope of the line describing the temperature-respiration relationship. The $E_{a}$ values were calculated using the Arrhenius equations as follows (Hamdi et al. 2013):

$R s=A \times e^{\frac{-E a}{R T}}$

$E a=R \times\left(\ln Q_{10}\right) /\left(\frac{1}{T_{1}}-\frac{1}{T_{2}}\right)$

where $A$ is a pre-exponential parameter; $R$ is the gas constant $\left(8.314 \mathrm{~J} \mathrm{~mol}^{-1}\right.$ ); and $T_{1}$ and $T_{2}$ indicate temperature $(K)$ and indicate the $10{ }^{\circ} \mathrm{C}$ temperature range for the corresponding $Q_{10}$ (i.e., $T_{1}+10=T_{2}$ ). In calculating $E_{a}, Q_{10}$ represented the range $T_{-5}$ to $T_{+5}$, where $T$ was the average incubation temperature. 
Statistical analysis

One-way analysis of variance (ANOVA) was used to compare soil water content, total $\mathrm{C}$ and $\mathrm{N}, \mathrm{pH}$, and conductivity among different locations. Univariate analysis was used to examine the effects of sampling location, temperature, incubation duration, and their interactions on $R \mathrm{~s}$. Differences in $Q_{10}$ between alpine wetland and meadow were examined using independent-sample $t$-tests. Regression analyses were used to evaluate the relationships between $C$ quality index and $E_{a}$. Significant differences were defined as $P=0.05$. All statistical analyses were conducted using SPSS 13.0 (SPSS Inc., Chicago, IL, USA).

\section{Results}

Changes in soil and vegetation

Soil water content decreased gradually and significantly (84-29\%) from locations I to V (Fig. 1; $F=196.233, P<0.001)$. Soil $\mathrm{C}$ and $\mathrm{N}$ content increased initially and then decreased from locations $\mathrm{I}$ to $\mathrm{V}$, and they were lowest in the alpine meadow $(\mathrm{V})$. Soil C content was significantly higher in wetlands than in meadow sites ( $F=10.194, P=0.004)$, but no significant differences were observed among different wetland locations (Table 1).

Effects of temperature and sampling location on $R s$

Sampling location, incubation temperature, and incubation duration significantly influenced the accumulation of SOM decomposition, and there was a significant interactive effect $(P<0.001$; Table 2$)$. Similarly, these variables significantly affected $R s$, and there was a significant interactive effect for sample position and temperature $(P<0.001$; Table 2$) . R s$ increased significantly with increasing incubation temperature at all sampling locations $(F=80.880, \quad P<0.001$, Table 2), which can be well depicted by exponential equations (Fig. 2). As expected, $R s$ increased gradually from location I to IV and then decreased drastically at location V, regardless of incubation duration (Fig. 3). Furthermore, $R s$ differed significantly in relation to soil moisture $(F=139.305, P<0.001$; Fig. 3, Table 2$)$, and showed a general trend of IV $>$ III $>$ II $>$ I $>$ V.

Changes in $Q_{10}$ and $E_{a}$ with soil moisture gradient

The $Q_{10}$ values ranged from 1.49 to 1.83 from locations $\mathrm{I}$ to $\mathrm{V}$, and were highest in the alpine meadow. Unexpectedly, $Q_{10}$ did not differ significantly from location I to IV, which represented a degradation gradient $\left(R^{2}=0.316, \quad P=0.352\right.$; Fig. 4c). However, the $Q_{10}$ values were significantly higher in the alpine meadow than in the wetland $(F=7.657, P<0.001$; Fig. 4 d $)$.

$E_{a}$ increased to some extent with decreasing soil moisture $\left(R^{2}=0.394, P=0.256\right.$; Fig. $\left.4 \mathrm{a}\right)$ and $E_{a}$ was highest in the alpine meadow. The average $E_{a}$ value in the wetland was significantly lower than that of the alpine meadow ( $F=5.713, P=0.010$; Fig. $4 b)$.

$E_{a}$ related to substrate quality

The $E_{a}$ values decreased significantly with increasing substrate quality index $(Q)$ for all locations. The logarithmic equations fit the negative relationships well $\left(R^{2}=0.254, \quad P<0.001 ;\right.$ Fig. 5a), and the

Table 2 Effects of sampling location, incubation temperature, and duration on SOM decomposition rates and accumulation

\begin{tabular}{lcccc}
\hline & \multicolumn{2}{c}{ Decomposition rate of SOM } & & \multicolumn{2}{c}{ Accumulation of SOM decomposition } \\
\cline { 2 - 3 } & $F$ & $p$ & $F$ & $p$ \\
\hline Sampling position (P) & 139.305 & $<0.001$ & 175.216 & $<0.001$ \\
Incubation temperature (T) & 80.880 & $<0.001$ & 111.805 & $<0.001$ \\
Incubation duration (D) & 6.927 & $<0.001$ & 152.974 & $<0.001$ \\
$\mathrm{P} \times \mathrm{T}$ & 4.298 & $<0.001$ & 5.800 & $<0.001$ \\
$\mathrm{P} \times \mathrm{D}$ & 0.413 & 0.990 & 7.393 & $<0.001$ \\
$\mathrm{~T} \times \mathrm{D}$ & 0.652 & 0.875 & 4.829 & $<0.001$ \\
$\mathrm{P} \times \mathrm{T} \times \mathrm{D}$ & 0.226 & 1.000 & 0.264 & 1.000 \\
\hline
\end{tabular}




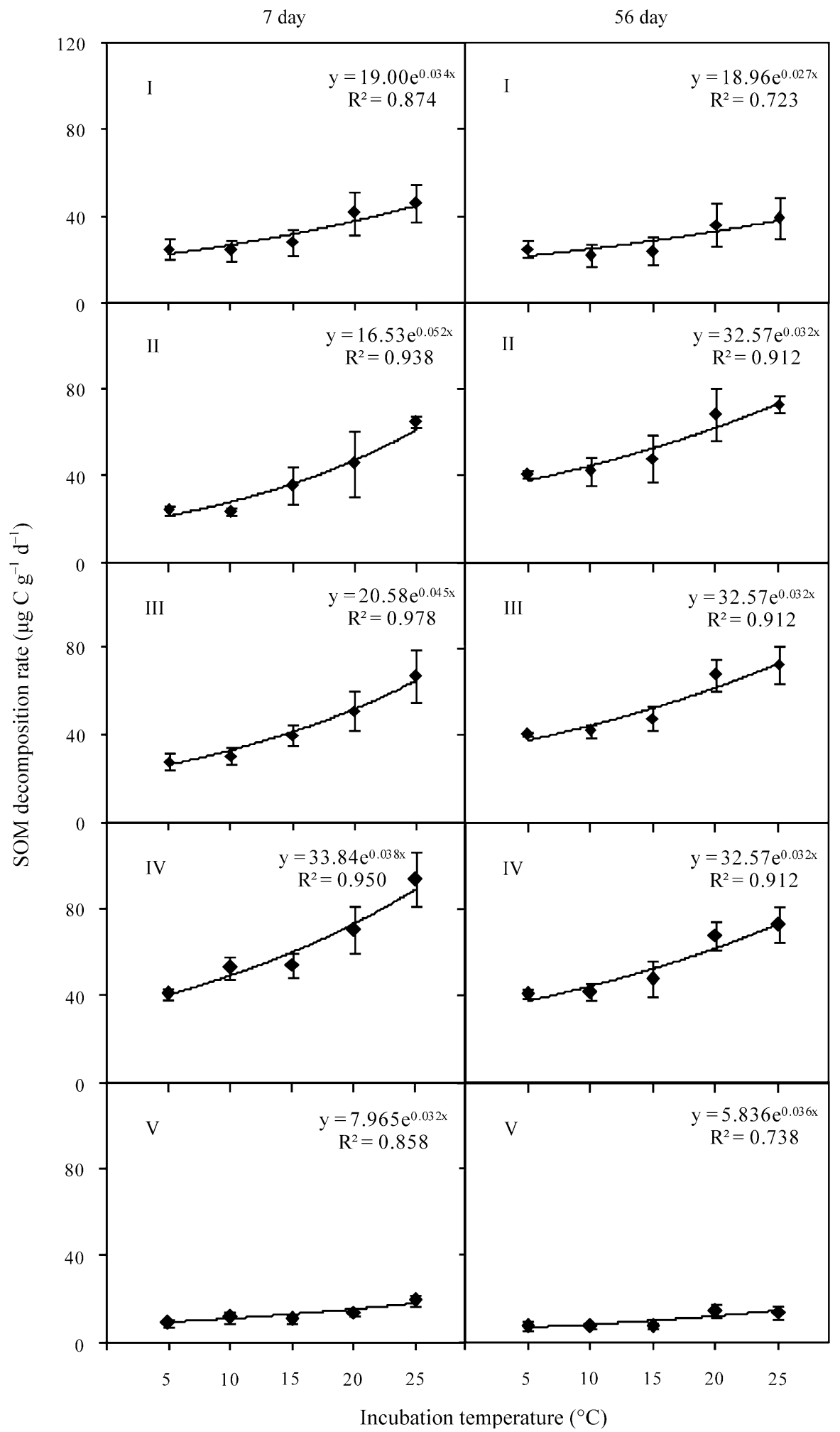

Fig. 2 Effect of incubation temperature on SOM decomposition rate in alpine wetland and meadow. I, II, III, IV, and V represent different sampling locations (Fig. 1). The data are mean $\pm \mathrm{SE}(n=9)$ 


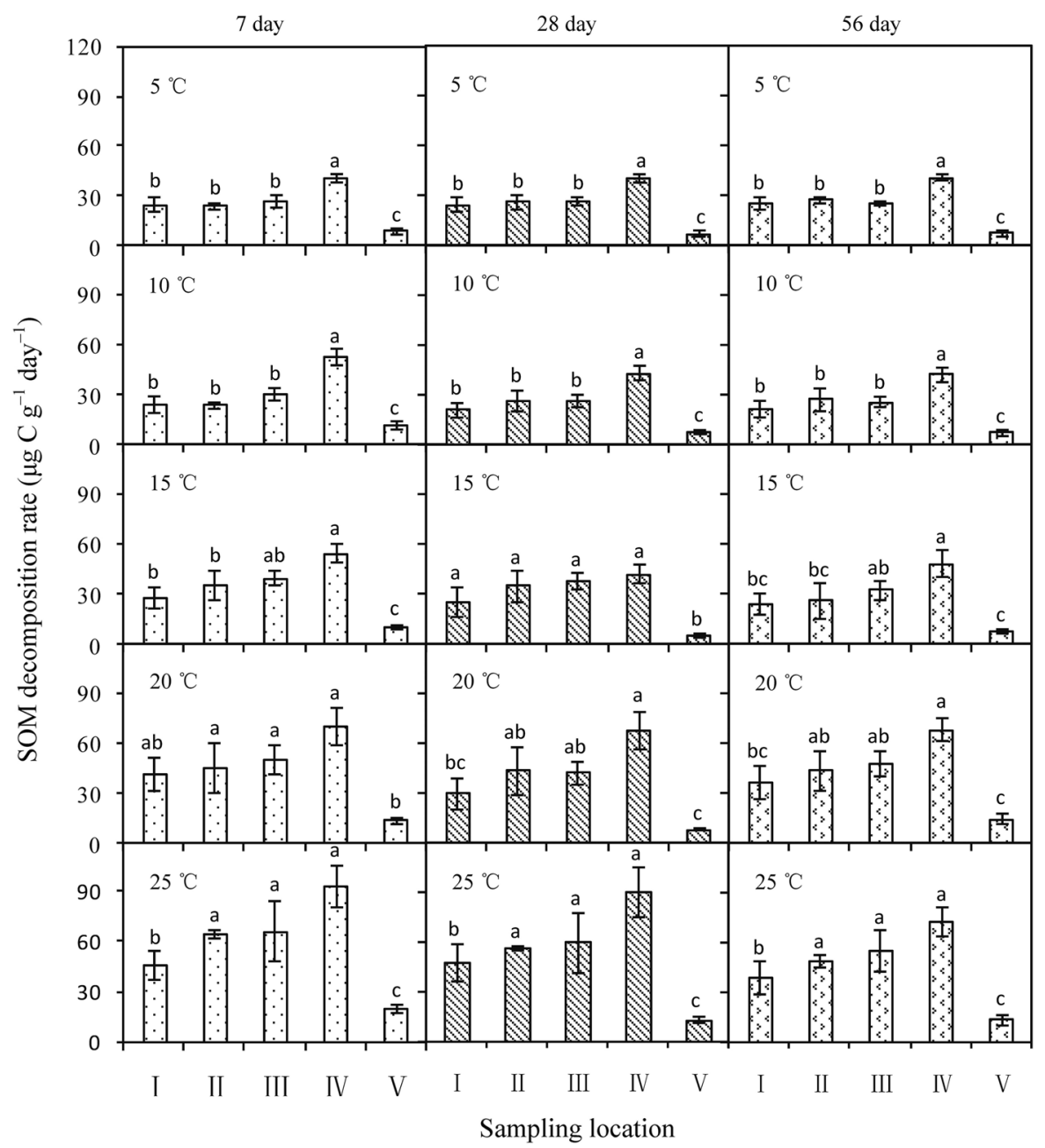

Fig. 3 Changes in SOM decomposition rates among different sampling positions. I, II, III, IV, and V indicate different sampling locations (Fig. 1). Data are mean $\pm \mathrm{SE}(n=9)$

relationship was stronger in the alpine meadow (site $\mathrm{V}$, Fig. 5f). Except for location III, $E_{a}$ deceased significantly with increasing $Q$ in the wetland sites $\left(R^{2}=0.147, \quad P=0.006 \quad\right.$ for $\mathrm{I} ; \quad R^{2}=0.093$, $P=0.034$ for II; $R^{2}=0.173, P=0.002$ for IV) (Fig. 5b-e).

\section{Discussion}

Rising temperature accelerates SOM decomposition in the alpine wetland

It has become clear that $R s$ is positively correlated with temperature (Du et al. 2014; Hartley and Ineson
2008; Jenkinson et al. 1991; Knorr et al. 2005; Mitsch and Gosselink 2007). Our findings demonstrated that $R s$ increased exponentially with increasing temperature in the Zoige alpine wetland and meadow. Similarly, Wang et al. (2010) reported that temperature played an important role in $R s$ in permafrost wetlands in the Great Hing' an Mountains of China. A study of Mediterranean forest soils in Italy showed that $R s$ increased exponentially with increasing temperature when soil moisture or other factors were not limiting (Rey et al. 2005). Higher temperatures are conducive to microbial activity and enzymatic activity increase with temperature; thus, increased temperatures in the future would improve substrate utilization and result in higher $R s$ (Craine et al. 2010b; 


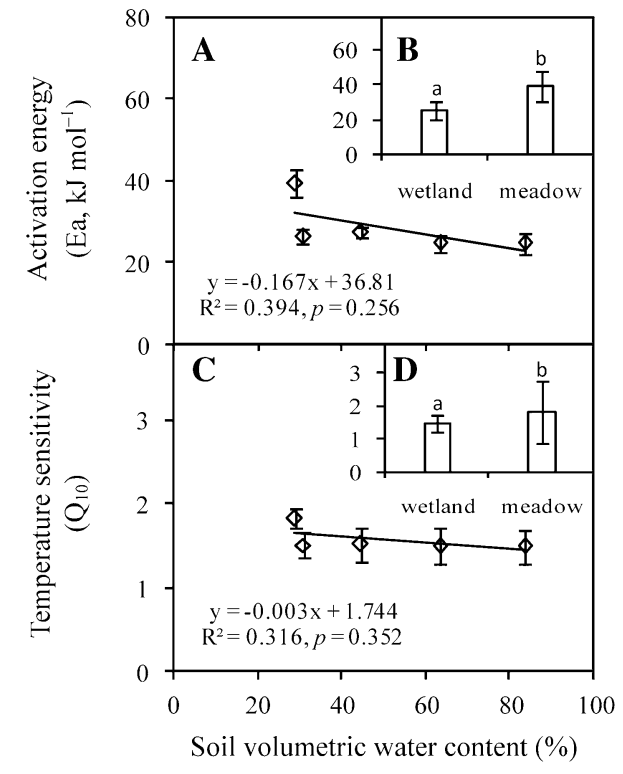

Fig. 4 Changes in activation energy $\left(E_{a}\right)$ and temperature sensitivity $\left(Q_{10}\right)$ with soil moisture gradient (sampling location). Data in scatter panels $(\mathbf{a}, \mathbf{c})$ represent $E_{a}$ and $Q_{10}$ of I, II, III, IV, and V. Data in inset column panels $(\mathbf{b}, \mathbf{d})$ are derived from wetlands (I, II, III, and IV) and meadow (V)

Gershenson et al. 2009; von Lutzow and KogelKnabner 2009).

Changes in substrate and microbial communtiy lead different SOM decomposition

The gradual increases in $R s$ with decreasing soil moisture in different wetlands indicate that changes in soil substrate and aerobic microbial communtiy lead the difference in SOM decomposition. The findings support our assumption that $R s$ may first increase and then decrease during the process of degradation of wetland to meadow. When moisture content is moderate, aerobic conditions promote soil enzyme activity, which accelerates SOM decomposition (Carrera et al. 2011; Toberman et al. 2008). Moreover, lower oxygen concentrations in saturated and inundated soils inhibit phenol oxidase activity; which results in the accumulation of phenolic compounds that inhibit the activity of hydrolase enzymes and reduce $R s$ (Freeman et al. 2001). However, this inhibition is quickly reversible when wetland soils become aerobic (Davidson and Janssens 2006), and can result in higher $R s$ and larger $C$ loss with the degradation process of alpine wetlands (Shang and Yang 2012; Tian et al. 2004).
The lower $R s$ observed in the alpine meadow may be linked to $\mathrm{C}$ constraints. Furthermore, some studies have demonstrated that changes in soil enzyme activity are important determinants resulting from lower C quality (Shackle et al. 2000) and different C content of different vegetation types (Neff and Hooper 2002).

The alpine wetland has lower temperature sensitivity than the alpine meadow

The significant differences in $Q_{10}$ between alpine wetlands and meadows provide new evidence that models involving specific $Q_{10}$ value can better predict the influences of warming climate on the $\mathrm{C}$ budget in alpine ecosystems. However, we did not observe a significant trend of $Q_{10}$ along the wetland degradation gradient. In a study of peatlands in northern Manitoba, Canada, Ise et al. (2008) found that a falling water table increased the sensitivity of peat decomposition to temperature. Soil water content in the alpine wetlands was high, which depressed air diffusion, enzyme activity, and substrate availability (Rey et al. 2005; Tang et al. 2012; Wang et al. 2010); this may have obscured the influences of increasing temperature and resulted in a lack of significant differences in $Q_{10}$ among different alpine wetlands. Moreover, the alpine wetlands were rich in high-quality SOM, therefore $Q_{10}$ values should not increase significantly until betterquality SOM is progressively depleted (Hartley and Ineson 2008). According to the CQT hypothesis, similar substrate quality is associated with similar $Q_{10}$ (Bosatta and Agren 1999; Craine et al. 2010b; Gershenson et al. 2009), which should explain the differences in temperature sensitivity between alpine wetland and alpine meadow to some extent.

C quality-temperature hypothesis is applicable to the alpine wetland and meadow

$E_{a}$ decreased logarithmically with increasing substrate quality in both alpine wetland and meadow, which supported the CQT hypothesis that the temperature sensitivity $\left(Q_{10}\right)$ of soil organic matter (SOM) decomposition is inversely related to organic carbon (C) quality or $E_{a}$ (Bosatta and Agren 1999; Xu et al. 2012). Substrate quality is particularly important (Giardina and Ryan 2000; Hartley et al. 2009; Mikan et al. 2002). Bosatta and Agren (1999) developed the 

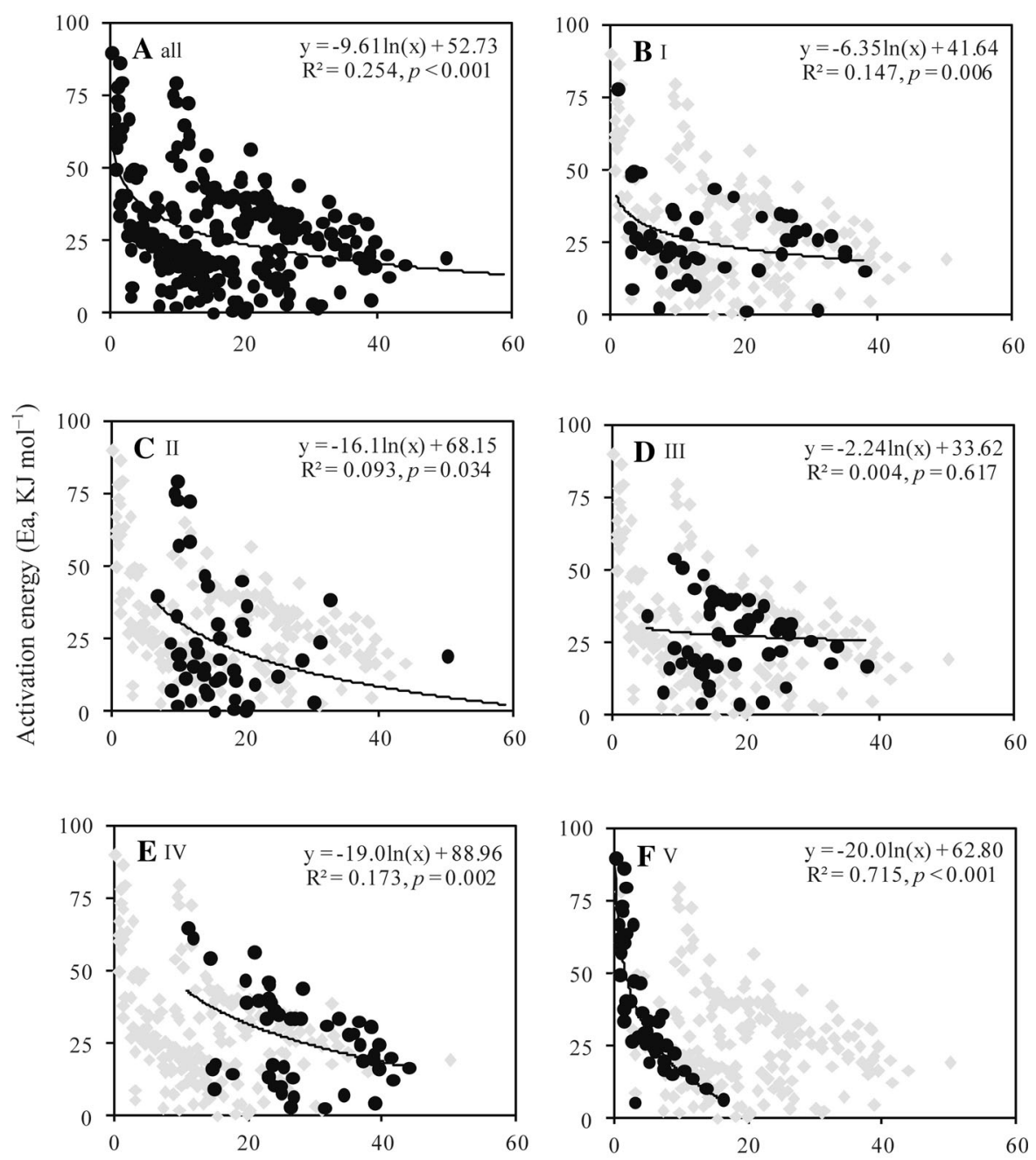

Substrate quality index (Q)

Fig. 5 Relationships between activation energy $\left(E_{a}\right)$ and substrate quality index $(Q)$ in alpine wetlands and meadows. The $Q$ values were calculated by exponential models $\left(S R=Q \times \mathrm{e}^{b T}\right)$. The grey points represent the relationship

CQT hypothesis based on principles of enzyme kinetics, wherein the energy required for SOM decomposition is correlated with substrate quality. In other words, the higher activation energy associated with the breakdown of recalcitrant substrates should result in greater $Q_{10}$ (Conen et al. 2008). In accordance with previous studies (Fierer et al. 2005; Koch et al. 2007; Wetterstedt et al. 2010), we used a C quality index calculated from exponential equations, and found that the observed $Q_{10}$ and $E_{a}$ were inversely related to substrate quality indices in both alpine between $E_{a}$ and $Q$ of all locations. The black points in $\mathbf{b}, \mathbf{c}, \mathbf{d}, \mathbf{e}$, and $\mathbf{f}$ represent the relationship between $E a$ and $Q$ in the locations I, II, III, IV, and V

wetland and meadow. Xu et al. (2012) also used the C quality index to represent the overall $\mathrm{C}$ quality of SOM being utilized by microbes at a special time point. Using different approaches, Hartley and Ineson (2008) found that $Q_{10}$ values increased significantly with incubation duration, suggesting that substrate recalcitrance increases as the labile SOC pool is depleted, and that incubation time could reflect substrate quality.

SOM decomposition rates in the Zoige alpine wetlands increased significantly with rising temperature. Lower $Q_{10}$ values in alpine wetlands could be 
explained by changes in soil moisture, enzyme activity, and substrate availability during the degradation process. The activation energy of SOM decomposition decreased logarithmically with increasing substrate quality in both alpine wetland and meadow, indicating that the CQT hypothesis is applicable to these types of sites. The influence of wetland degradation on the $Q_{10}$ of SOM decomposition provides new insights to improve the prediction of $\mathrm{C}$ budget in alpine wetlands under warming scenarios.

Acknowledgments This work was partially supported by Natural Science Foundation of China (31470506 and 31270519), and the Program for Kezhen Distinguished Talents in Institute of Geographic Sciences and Natural Resources Research, CAS (2013RC102).

\section{References}

Bai JH, Lu QQ, Zhao QQ, Wang JJ, Ouyang H (2013) Effects of alpine wetland landscapes on regional climate on the Zoige plateau of China. Adv Meteorol. doi:10.1155/2013/972430

Bauer J, Herbst M, Huisman JA, Weihermuller L, Vereecken H (2008) Sensitivity of simulated soil heterotrophic respiration to temperature and moisture reduction functions. Geoderma 145:17-27

Bosatta E, Agren GI (1999) Soil organic matter quality interpreted thermodynamically. Soil Biol Biochem 31:1889-1891

Carrera N, Barreal ME, Rodeiro J, Briones MJI (2011) Interactive effects of temperature, soil moisture and enchytraeid activities on $\mathrm{C}$ losses from a peatland soil. Pedobiologia 54:291-299

Chen H, Wang M, Wu N, Wang YF, Zhu D, Gao YH, Peng CH (2011) Nitrous oxide fluxes from the littoral zone of a lake on the Qinghai-Tibetan Plateau. Environ Monit Assess 182:545-553

Conant RT, Steinweg JM, Haddix ML, Paul EA, Plante AF, Six J (2008) Experimental warming shows that decomposition temperature sensitivity increases with soil organic matter recalcitrance. Ecology 89:2384-2391

Conen F, Karhu K, Leifeld J, Seth B, Vanhala P, Liski J, Alewell C (2008) Temperature sensitivity of young and old soil carbon-same soil, slight differences in $\mathrm{C}^{-13}$ natural abundance method, inconsistent results. Soil Biol Biochem 40:2703-2705

Craine J, Spurr R, Mclauchlan K, Fierer N (2010a) Landscapelevel variation in temperature sensitivity of soil organic carbon decomposition. Soil Biol Biochem 42:373-375

Craine JM, Fierer N, Mclauchlan KK (2010b) Widespread coupling between the rate and temperature sensitivity of organic matter decay. Nat Geosci 3:854-857

Davidson EA, Janssens IA (2006) Temperature sensitivity of soil carbon decomposition and feedbacks to climate change. Nature 440:165-173
De Bruijn AMG, Butterbach-Bahl K (2010) Linking carbon and nitrogen mineralization with microbial responses to substrate availability-the DECONIT model. Plant Soil 328:271-290

Du BM, Kang HZ, Pumpanen J et al (2014) Soil organic carbon stock and chemical composition along an altitude gradient in the Lushan Mountain, subtropical China. Ecol Res 29:433-439

Fang CM, Smith P, Moncrieff JB, Smith JU (2005) Similar response of labile and resistant soil organic matter pools to changes in temperature. Nature 433:57-59

Fei S, Cui L, He S, Chen X, Jiang J (2006) A background study of the wetland ecosystem research station in the Ruoergai plateau. J Sichuan For Sci Technol 27:21-29

Fierer N, Allen AS, Schimel JP, Holden PA (2003) Controls on microbial $\mathrm{CO}_{2}$ production: a comparison of surface and subsurface soil horizons. Glob Change Biol 9:1322-1332

Fierer N, Craine JM, Mclauchlan K, Schimel JP (2005) Litter quality and the temperature sensitivity of decomposition. Ecology 86:320-326

Fierer N, Colman BP, Schimel JP, Jackson RB (2006) Predicting the temperature dependence of microbial respiration in soil: a continental-scale analysis. Glob Biogeochem Cycles. doi:10.1029/2005GB002644

Freeman C, Ostle N, Kang H (2001) An enzymatic 'latch' on a global carbon store. Nature 409:149

Froend JA (1999) Loss and degradation of wetlands in southwestern Australia underlying causes, consequences and solutions. Wetlands Ecol Manage 7:13-23

Gao JQ, Zhang F, Wang CM (2008) Distribution characteristics of soil libile carbon along water table gradient of alpine wetland soil. J Soil Water Conserv 22:126-131

Gershenson A, Bader NE, Cheng WX (2009) Effects of substrate availability on the temperature sensitivity of soil organic matter decomposition. Glob Change Biol 15:176-183

Giardina CP, Ryan MG (2000) Evidence that decomposition rates of organic carbon in mineral soil do not vary with temperature. Nature 404:858-861

Gilbert C, Sigua JG, Kang WJ, Coleman SW (2004) Wetland conversion to beef cattle pasture changes in soil properties. J Soils Sediments 4:4-10

Gillabel J, Cebrian-Lopez B, Six J, Merckx R (2010) Experimental evidence for the attenuating effect of SOM protection on temperature sensitivity of SOM decomposition. Glob Change Biol 16:2789-2798

Gillespie AW, Sanei H, Diochon A et al (2014) Perennially and annually frozen soil carbon differ in their susceptibility to decomposition: analysis of Subarctic earth hummocks by bioassay, XANES and pyrolysis. Soil Biol Biochem 68:106-116

Hamdi S, Moyano F, Sall S, Bernoux M, Chevallier T (2013) Synthesis analysis of the temperature sensitivity of soil respiration from laboratory studies in relation to incubation methods and soil conditions. Soil Biol Biochem 58:115-126

Hart EA, Lovvorn JR (2000) Vegetation dynamics and primary production in saline, lacustrine wetlands of a Rocky Mountain basin. Aquat Bot 66:21-39 
Hartley IP, Ineson P (2008) Substrate quality and the temperature sensitivity of soil organic matter decomposition. Soil Biol Biochem 40:1567-1574

Hartley IP, Hopkins DW, Garnett MH, Sommerkorn M, Wookey PA et al (2009) No evidence for compensatory thermal adaptation of soil microbial respiration in the study of Bradford et al. (2008). Ecol Lett 12:E12-E14

He NP, Wang RM, Gao Y, Dai JZ, Wen XF, Yu GR (2013) Changes in the temperature sensitivity of SOM decomposition with grassland succession: implications for soil $\mathrm{C}$ sequestration. Ecol Evol 3:5045-5054

Huo L, Chen Z, Zou Y, Lu X, Guo J, Tang X (2013) Effect of Zoige alpine wetland degradation on the density and fractions of soil organic carbon. Ecol Eng 51:287-295

Ise T, Dunn AL, Wofsy SC, Moorcroft PR (2008) High sensitivity of peat decomposition to climate change through water-table feedback. Nat Geosci 1:763-766

Jenkinson DS, Adams DE, Wild A (1991) Model estimates of $\mathrm{CO}_{2}$ emissions from soil in response to global warming. Nature 351:304-306

Jin HJ, Yu QH, Lii LZ et al (2007) Degradation of permafrost in the Xing'anling Mountains, northeastern China. Permafrost Periglac Process 18:245-258

Jones CD, Cox P, Huntingford C (2003) Uncertainty in climatecarbon-cycle projections associated with the sensitivity of soil respiration to temperature. Tellus Ser B Chem Phys Meteorol 55:642-648

Kirschbaum MUF (2000) Will changes in soil organic carbon act as a positive or negative feedback on global warming? Biogeochemistry 48:21-51

Kirschbaum MUF (2006) The temperature dependence of organic-matter decomposition-still a topic of debate. Soil Biol Biochem 38:2510-2518

Knorr W, Prentice IC, House JI, Holland EA (2005) Long-term sensitivity of soil carbon turnover to warming. Nature 433:298-301

Koch O, Tscherko D, Kandeler E (2007) Temperature sensitivity of microbial respiration, nitrogen mineralization, and potential soil enzyme activities in organic alpine soils. Global Biogeochem Cycles. doi:10.1029/2007GB002983

Lenton TM, Huntingford C (2003) Global terrestrial carbon storage and uncertainties in its temperature sensitivity examined with a simple model. Glob Change Biol 9:1333-1352

Limpens J, Berendse F, Blodau C, Canadell JG, Freeman C, Holden J, Roulet N, Rydin H, Schaepman-Strub G (2008) Peatlands and the carbon cycle: from local processes to global implications - a synthesis. Biogeosciences 5:1475-1491

Mikan CJ, Schimel JP, Doyle AP (2002) Temperature controls of microbial respiration in arctic tundra soils above and below freezing. Soil Biol Biochem 34:1785-1795

Mitsch WJ, Gosselink JG (2007) Wetlands. Wiley, Hoboken

Neff JC, Hooper DU (2002) Vegetation and climate controls on potential $\mathrm{CO}_{2}$, DOC and DON production in northern latitude soils. Glob Change Biol 8:872-884
Rey A, Petsikos C, Jarvis PG, Grace J (2005) Effect of temperature and moisture on rates of carbon mineralization in a Mediterranean oak forest soil under controlled and field conditions. Eur J Soil Sci 56:589-599

Shackle VJ, Freeman C, Reynolds B (2000) Carbon supply and the regulation of enzyme activity in constructed wetlands. Soil Biol Biochem 32:1935-1940

Shang W, Yang YX (2012) Degradation characteristics, patterns, and processess of lakeside wetland in Napahai of northwest Yunnan Plateau, Southwest China. Chin J Appl Ecol 23:3257-3265

Sierra J, Brisson N, Ripoche D, Deque M (2010) Modelling the impact of thermal adaptation of soil microorganisms and crop system on the dynamics of organic matter in a tropical soil under a climate change scenario. Ecol Model 221:2850-2858

Tan YY, Wang X, Li CH, Cai YP, Yang ZF, Wang YL (2012) Estimation of ecological flow requirement in Zoige Alpine Wetland of southwest China. Environ Earth Sci 66:1525-1533

Tang J, Ding X, Wang LM et al (2012) Effects of wetland degradation on bacterial community in the Zoige Wetland of Qinghai-Tibetan Plateau (China). World J Microbiol Biotechnol 28:649-657

Tian YB, Xiong MB, Gy Song (2004) Study on change of soil organic matter in the process of wetland ecological restoration in Ruoergai plateau. Wetland Sci 2:88-93

Toberman H, Evans CD, Freeman C, Fenner N, White M, Emmett BA, Artz Rebekka RE (2008) Summer drought effects upon soil and litter extracellular phenol oxidase activity and soluble carbon release in an upland Calluna heathland. Soil Biol Biochem 40:1519-1532

Von Lutzow M, Kogel-Knabner I (2009) Temperature sensitivity of soil organic matter decomposition-what do we know? Biol Fertil Soils 46:1-15

Wang XW, Li XZ, Hu YM, Lv JJ, Sun J, Li ZM, Wu ZF (2010) Effect of temperature and moisture on soil organic carbon mineralization of predominantly permafrost peatland in the Great Hing'an Mountains, Northeastern China. J Environ Sci China 22:1057-1066

Wetterstedt JA, Persson T, Agren GI (2010) Temperature sensitivity and substrate quality in soil organic matter decomposition: results of an incubation study with three substrates. Glob Change Biol 16:1806-1819

Xiang W, Freeman C (2009) Annual variation of temperature sensitivity of soil organic carbon decomposition in North peatlands: implications for thermal responses of carbon cycling to global warming. Environ Geol 58:499-508

Xu X, Luo Y, Zhou J (2012) Carbon quality and the temperature sensitivity of soil organic carbon decomposition in a tallgrass prairie. Soil Biol Biochem 50:142-148

Zhang Y, Wang GX, Wang YB (2011) Changes in alpine wetland ecosystems of the Qinghai-Tibetan plateau from 1967 to 2004. Environ Monit Assess 180:189-199 